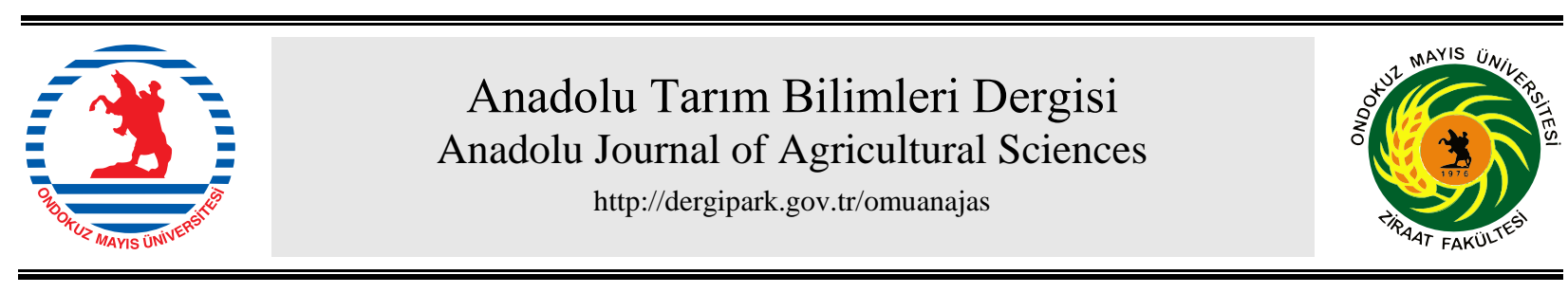

Araştırma/Research

Anadolu Tarım Bilim. Derg./Anadolu J Agr Sci, 32 (2017)

ISSN: 1308-8750 (Print) 1308-8769 (Online)

doi: 10.7161/omuanajas.343724

\title{
Yenibahar (Pimenta dioica L.) meyvesinin bazı fiziksel özelliklerinin belirlenmesi
}

\author{
Ebubekir Altuntaş ${ }^{*}$, Müberra Erdoğan \\ Gaziosmanpaşa Üniversitesi, Ziraat Fakültesi, Biyosistem Mühendisliği Bölümü \\ *Sorumlu yazar/corresponding author: ebubekir.altuntas@gop.edu.tr
}

Geliş/Received 21/04/2017 Kabul/Accepted 21/09/2017

\begin{abstract}
ÖZET
Bu çalışmada, Pimenta dioica L. bitkisinin kurutulmuş meyvesi olan yenibahar meyvesi (newspice, allspice) ve tohumlarının bazı fiziksel özelliklerinin belirlenmesi amaçlanmıştır. Çalışma kapsamında yenibahar meyvesi ve tohumlarının geometrik ortalama çapı, yüzey alanı, hacmi, gerçek ve yığın hacim ağırlıkları, renk özellikleri, mekanik özellikler ile sürtünme katsayısına ait değerler belirlenmiştir. Buna göre, yenibahar meyvesi ve tohumları geometrik ortalama çap değerleri $7.97 \mathrm{~mm}$ ve $4.18 \mathrm{~mm}$, yüzey alanı değerleri ise $2.11 \mathrm{~cm}^{2}$ ve $0.553 \mathrm{~cm}^{2}$ olarak saptanmıştır. Bununla birlikte yenibahar meyvesi ve tohumlarının ağırlıkları sırasıyla $0.18 \mathrm{~g}$ ve $0.065 \mathrm{~g}$ olarak bulunurken, gerçek hacim ağırlıkları sırasıyla $897.72 \mathrm{~kg} \mathrm{~m}^{-3}$ ve $1892.3 \mathrm{~kg} \mathrm{~m}^{-3}$ olarak belirlenmiştir. Yenibahar meyvelerinin renk ölçümlerindeki karakteristik $L^{*}, a^{*}, b^{*}$ değerleri sırasıyla 34.2, 5.53, 2.67 olarak bulunurken, yenibahar tohumlarının $\left(L^{*}, a^{*}, b^{*}\right)$ değerleri sırasıyla 32.8, 5.56, 1.32 olarak bulunmuştur. Yenibahar meyvelerinin statik sürtünme katsayısı değerleri en düşük ve en yüksek sırasıyla cam ve lastik yüzeyde bulunmuştur. Yenibahar meyvesinin kırılma kuvveti X, Y ve Z eksenleri için $60 \mathrm{~mm} \mathrm{~h}^{-1}$ hızında sırasıyla 25.74, 27.40, $38.48 \mathrm{~N}$ olarak bulunmuştur. Yenibahar meyvesi ve tohumlarının geometrik, volumetrik ve mekanik özellikleri hasat sonrası uygulamalarda kullanılan alet ve ekipmanların tasarımına katkı sunacak, ve ekonomik değerini artıracaktır.
\end{abstract}

\section{Determination of some physical properties of allspice (Pimenta dioica L.) fruit}

\section{ABSTRACT}

Allspice is the dried fruit of the Pimenta dioica plant. In this study, some physical properties of allspice were determined. The geometric mean diameter, surface area, volume, true and bulk densities and static friction coefficient values of allspice fruit and seed were determined. The geometric mean diameter values of the fruit and seed of allspices were as $7.97 \mathrm{~mm}$ and $4.18 \mathrm{~mm}$, whereas, the surface area values were as $2.11 \mathrm{~cm}^{2}$ ve $0.553 \mathrm{~cm}^{2}$, respectively. The fruit masses of fruit and seed of the allspices were as $0.18 \mathrm{~g}$ and $0.065 \mathrm{~g}$, whereas, the true densities of fruit and seed of the allspice fruit were as 897.72 $\mathrm{kgm}^{-3}$ ve $1892.3 \mathrm{~kg} \mathrm{~m}^{-3}$, respectively. Colour characteristics $\left(L^{*}, a^{*}, b^{*}\right)$ of allspice fruits were obtained as $34.2,5.53,2.67$; whereas $\left(L^{*}, a^{*}, b^{*}\right)$ of allspice seeds were found as $32.8,5.56,1.32$, respectively. The lowest and highest static coefficient of friction values of allspice fruits were found for glass and rubber surfaces, respectively. Rupture force of allspice fruits along $\mathrm{X}, \mathrm{Y}, \mathrm{Z}$ axes at $60 \mathrm{~mm} \mathrm{~min}^{-1}$ compression speed were obtained as $25.74,27.40,38.48 \mathrm{~N}$, respectively. Geometric, volumetric, colour and mechanical properties of allspice fruit and seeds will serve to design the equipment used in postharvest treatments and will increase their economic value.
Anahtar Sözcükler:

Yenibahar

Geometrik özellikleri

Renk özellikleri

Mekanik özellikler
Keywords:

Allspice

Geometric properties

Colour properties

Mechanical properties

\section{Giriş}

Mersingiller familyasının yaprağını dökmeyen bir üyesi olan yenibahar veya diğer adıyla "Jamaika Biberi”, genel olarak Amerika'nın tropikal bölgelerinde yetişen bir bitkinin meyvelerinin yeşilken koparılıp kurutulması sonucu elde edilir. Oldukça kokulu bir baharat olan yenibahar; hindistan cevizi, tarçın, karanfil, kakule, karabiber, zencefil gibi birçok baharatın kokusunu içermesinden dolayı İngilizcede "Allspice" yani "tüm baharatlar" olarak adlandırılmaktadır (Anonim, 2017a; Peter, 2004). Yenibahar bitkisi, 1494'te Columbus tarafindan karabiber ile ilgili yeni kaynaklar araştırılırken keşfedilmiştir. Adını tarçın, biber, karanfil ve ardıç çileklerinin birleşimi olarak tanımlanan meyve tadından alır. Bitki adı 'pimenta' 
(Portekizce) ve 'pimienta' (İspanyolca) 'biber' anlamındadır. Ayrıca Orta Amerika ve Meksika'da yetiştirilmektedir (Anonim, 2017b; Peter, 2004).

Yenibahar meyvelerinin temel bileşenlerine bakıldığında \% 2.5 esansiyel yağ içermektedir. Ana bileşenler olarak ojenol, ojenol metil eter ve terpenler (mirken, 1,8-sineol ve $\alpha$-phellandrene) bulunmaktadır. Jamaika'daki meyvelerde, ojenol (\% 65-90) ana bileşendir; Meksika'daki meyvelerde ise az miktarda mirsen (\%15) ve ojenol (\%10) ile metil ojenol (\% 5060) hakimdir (Anonim, 2017c).

Pimenta dioica L. bitkisinin kurutulmuş meyvesi olan yenibahar meyvesidir. Kurutulmuş meyveler pimenta ticari çeşididir. Hasat edilen meyvelerin kurutma işlemi 5-10 gün sürmekte ve nem içeriği \% 1214 nem düzeyine kadar düşürülmektedir (Peter, 2004). Yenibahar çeșitli yemeklerde baharat olarak kullanılır. Kullanıldığı yemeklere güzel bir tat ve hoş bir koku vermektedir. Baharat olarak kullanılmasının yanında birçok faydası da bulunmaktadır. Örnek olarak antiseptik, anestetik, analjezik ve antioksidan özellikleri bulunan yenibahar vücutta pek çok hastalığa neden olabilen serbest radikallere karşı koruma sağlamak, damar sertliğini önlemek, hazmı kolaylaştırmak, vücut direncini artırmak, unutkanlığ 1 gidermek vb. sayllabilir (Anonim, 2017d). Yenibahar meyve ve tohumlarının fiziksel özelliklerinin bilinmesi, ürünlerin ekimi, hasat ve hasat sonrası kullanılacak makine, enerji ve tarımsal yapı sistemlerinin tasarımında ve üretilmesinde önemli olmaktadır. Fiziksel özellikler; ürünün uzunluk, kalınlık, genişlik gibi temel boyutları ve temel boyutlar kullanılarak küresellik, geometrik ortalama çap, yüzey alanı ve hacim hesabı, bin tane ağırlığı, gözenekliliği, hacim ağırlığı, tane yoğunluğu, yığılma açısı, sürtünme katsayısı vb. parametreleridir.

Hasat ve hasat sonrası mekanizasyon tarımsal üretimde en önemli aşamalardan birisidir. Son yıllarda farklı ürün grupları içinde farklı hasat-harman ve hasat sonrası ürün işleme sistemlerinin geliştirilmesinde tıbbi ve aromatik bitkiler önemli bir çalışma alanı oluşturmuştur. Tibbi ve aromatik bitkiler ile ilgili hasatharman mekanizasyonu ve hasat sonrası ürün işleme teknolojisinin oluşturulmasına yönelik teknolojiler ülkemizde geliştirilememiş olup, tıbbi ve aromatik bitkilerin hasadı elle ya da biçerbağlarla çiçeklenme döneminde yapılmakta, harmanı ise belirli bir süre kurutulduktan sonra birbirine çarptırılarak gerçekleştirilmektedir. $\mathrm{Bu}$ durum iş gücüne, bitkilerde ürün kaybına, zedelenmeye yol açmaktadır. Tıbbi ve aromatik bitkilerin hasadı, harmanı, taşınması ve paketlenmesi gibi üretim aşamalarında karşılaşılan bu olumsuzlukların en aza indirilebilmesi için bitkilerin fiziko-mekanik özelliklerinin bilinmesi gerekmektedir (Gökduman, 2015). Yenibahar meyvesi ve tohumlarının fiziko-mekanik özellikleriyle ilgili herhangi bir bilimsel literatüre rastlanmamıştır. $\mathrm{Bu}$ nedenle, bu çalışmada, yenibahar meyvesi ve tohumlarının bazı fiziko-mekanik özellikleri belirlenmiştir.

\section{Materyal ve Yöntem}

Yenibahar meyvesi ve tohumları Tokat İlinde baharat bitkileri satan bir marketten temin edilmiştir. Ybahar meyvesi ve tohumları Gaziosmanpaşa Üniversitesi Ziraat Fakültesi Biyosistem Mühendisliği Bölümü Biyolojik Malzeme Laboratuarında denemeye alınmadan önce, örnekler arasındaki kırık, zedeli, şekilsiz ve diğer yabancı materyallerden ayıklanmıştır. Yenibahar meyveleri ve tohumlarının nem içerikleri için örnek materyaller $105{ }^{\circ} \mathrm{C}$ sicaklıkta $24 \mathrm{~h}$ etüvde kurutulmasiyla ve kuru baza göre bulunmuştur (Yurtlu ve ark., 2010).Yenibahar meyvesi ve tohumlarının nem içerikleri sırasıyla $\% \quad 9.14$ ve $\% \quad 10.19$ olarak belirlenmiştir.

Yenibahar meyvesi ve tohumlarının rastgele seçilen 100 adet materyaller üzerinde e yapılan ölçümlerde uzunluk, genişlik ve kalınlık değerleri ölçülmüştür. Uzunluk, genişlik ve kalınlık ölçümleri $0.01 \mathrm{~mm}$ hassasiyetli dijital kumpas kullanılarak gerçekleştirilmiştir. Ağırlıkları $0.001 \mathrm{~g}$ hassasiyetli elektronik bir terazide ölçülerek meyve tohumların birim ağırlıkları tespit edilmiştir. Meyve ve tohumların geometrik ortalama çapları $\left(D_{g}\right)$ ve küresellik değerleri $(\phi)$ ve yüzey alanları $(S)$ 'nın aşağıda verilen eşitlikler kullanılarak belirlenmiştir (Mohsenin, 1970):

$$
\begin{aligned}
& D_{g}(L W T)^{1 / 3} \\
& \phi=\left[\frac{D_{g}}{L}\right] \\
& S=\pi\left(D_{g}\right)^{2}
\end{aligned}
$$

Eşitliklerde; $L$ : uzunluk (mm), W: genişlik (mm); $T$ : kalınlık $(\mathrm{mm}) ; D_{g}$ : geometrik ortalama çap $(\mathrm{mm}) ; S$ : yüzey alanı $\left(\mathrm{mm}^{2}\right)^{\prime}$ dir.

Yenibahar meyve ve tohumlarının yığın hacim ağırlığı için hektolitre yöntemi kullanılmış olup, meyve hacim ağırlığı için sıvı yer değiş̧irme metodu ve saf su kullanılarak tespit edilmiştir. Gözeneklilik $(\varepsilon)$ değerinin belirlenmesinde ise aşağıda verilen eşitlik kullanılarak belirlenmiştir (Mohsenin, 1970; Altuntas, 2008):

$$
\varepsilon=\left[1-\frac{\rho_{b}}{\rho_{f}}\right] \times 100
$$

Eşitlikte; $\varepsilon$ : gözeneklilik (\%); $\rho_{b}$ : yı̆̆ın hacim ağırlığı $\left(\mathrm{kg} \mathrm{m}^{-3}\right)$ ve $\rho_{f}:$ meyve hacim ağırlığ $\left(\mathrm{kg} \mathrm{m}^{-3}\right)^{\prime}$ dır.

Denemelerde yenibahar meyvesi ve tohumlarının geometrik özelliklerinin belirlenmesi için rastgele 100 adet meyve ve tohum seçilmiştir. Volumetrik, renk ve mekanik özelliklerle ilgili rastgele 45 meyve ve tohum kullanılmıştır.

Yenibahar meyvesi ve tohumlarının renk karakteristikleri CR-400 model bir renk ölçer yardımıyla (Minolta, CR-400, Tokyo, Japonya), tespit edilmiştir. Yenibahar meyvesi ve tohumlarının renkleri CIE $L^{*}, a^{*}$ ve $b^{*}$ cinsinden belirlenmiştir. Hazırlanan 
skalaya göre, $L^{*}$ değeri; parlaklık, 0 karanlık, 100 aydınlık, $a^{*}$ değeri; + değerler kırmızılığı, - değerler yeşilliği ve $b^{*}$ değeri ise; + değerler sarılığ 1 , - değerler maviliği ifade etmektedir. (Jha ve ark., 2005; McGuire, 1992).

Yenibahar meyvesi ve tohumlarının farklı yüzeylerdeki (galvaniz metal, cam, PVC, kontrplak ve lastik) sürtünme katsayılarının ölçümünde eğimli masa deney düzeneği kullanılmıştır. Yenibahar meyvesi ve tohumlarının yüzey üzerinde bir vidalı kol yardımıyla eğimli masada belirli açı yapılacak şekilde yükseltilmesi sağlanmıştır. Yenibahar meyvesi ve tohumlarının ilk hareketine kadar elde edilen yatay ve düşey yükseklikler kaydedilerek, sürtünme yüzeyinin yatay düzlemle yaptığı açının tanjantı statik sürtünme katsayı değeri olarak belirlenmiștir (Celik ve ark., 2007).

Yenibahar meyvesi ve tohumlarının mekanik özellikleri, SH-2, 500 N (Sundoo SH-2, 500 N Çin) biyolojik materyal test cihazı kullanılarak saptanmıştır. Yenibahar meyvesi ve tohumlarının sıkıştırma testleri için, meyve ve tohum örnekleri üzerinden $14.87 \mathrm{~mm}$ çaplı plaka ile X (uzunluk), Y (genişlik) ve Z (kalınlık) eksenleri boyunca ölçümler yapılmıştır (Altuntas ve Erkol, 2011; Yurtlu ve ark., 2010).

\section{Bulgular ve Tartışma}

\subsection{Geometrik ve volumetrik özellikler}

Yenibahar meyvesi ve tohumlarının fiziksel ve mekanik özelliklerine ait ortalama ve standart sapma değerleri, Çizelge 1, 2 ve 3'de verilmiştir. Yenibahar meyvesi ve tohumlarının geometrik özellikleri kapsamında uzunluk, genişlik ve kalınlık değerlerinin ortalaması sırasıyla; meyveler için; 7.80, 8.07ve 8.01 $\mathrm{mm}$, tohumlar için; 5.46, 4.65 ve $2.92 \mathrm{~mm}$ olarak belirlenmiştir.

Yenibahar meyvesi ve tohumlarının geometrik ortalama çap ve küresellik değerleri sırasıyla; $7.97 \mathrm{~mm}$ ve 0.97 , tohumlar için; $4.18 \mathrm{~mm}$ ve 0.76 olarak saptanmıştır. Yenibahar meyvesi ve tohumlarının yüzey alanı değerleri ise sırasıyla; $2.11 \mathrm{~cm}^{2}$ ve $0.553 \mathrm{~cm}^{2}$ olarak belirlenmiştir (Çizelge 1). Volumetrik özellikler yenibahar meyvesi ve tohumları için incelendiğinde, meyve ağırlığı sırasıyla 0.18 ve $0.065 \mathrm{~g}$, meyve hacmi değerleri 2.67 ve $0.392 \mathrm{~cm}^{3}$, yığın hacim ağırlıkları 714.76 ve $538.67 \mathrm{~kg} \mathrm{~m}^{-3}$, meyve hacim ağırlıkları ise 897.72 ve $1892.3 \mathrm{~kg} \mathrm{~m}^{-3}$ olarak bulunmuştur. Meyve hasat sonrası depolama yapılarında kullanılacak önemli bir parametre olan gözeneklilik değeri ise, yenibahar meyvesi için \%18.46 olarak belirlenmiştir.

Çizelge 1. Yenibahar meyvesi ve tohumlarının bazı geometrik ve volumetrik özellikleri

\begin{tabular}{|c|c|c|c|c|}
\hline \multirow{2}{*}{$\begin{array}{c}\text { Fiziksel özellikler } \\
\text { Geometrik ve volumetrik özellikler }\end{array}$} & \multicolumn{2}{|c|}{ Meyve } & \multicolumn{2}{|c|}{ Tohum } \\
\hline & Ortalama & S.H $(*)$ & Ortalama & S.H $(*)$ \\
\hline Uzunluk, $L(\mathrm{~mm})$ & 7.80 & 0.627 & 5.46 & 0.412 \\
\hline Genişlik, $W(\mathrm{~mm})$ & 8.07 & 0.560 & 4.65 & 0.646 \\
\hline Kalınlık, $T(\mathrm{~mm})$ & 8.01 & 0.598 & 2.92 & 0.437 \\
\hline Geometrik ortalama çap, $D_{g}(\mathrm{~mm})$ & 7.97 & 0.421 & 4.18 & 0.353 \\
\hline Küresellik, $\phi$ & 0.97 & 0.015 & 0.76 & 0.052 \\
\hline Meyve ağırlığı, $M(\mathrm{~g})$ & 0.18 & 0.059 & 0.065 & 0.083 \\
\hline Yı̆̆ın hacim ağırlı̆̆ı,$\rho_{b}\left(\mathrm{~kg} \mathrm{~m}^{-3}\right)$ & 714.76 & 10.00 & 538.67 & 10.00 \\
\hline Meyve hacim ağırlığ $1, \rho_{f}\left(\mathrm{~kg} \mathrm{~m}^{-3}\right)$ & 897.72 & 67.00 & 1892.3 & 19.00 \\
\hline Gözeneklilik, $\varepsilon(\%)$ & 18.46 & 6.3 & 68.8 & 3.55 \\
\hline Yüzey alanı, S $\left(\mathrm{cm}^{2}\right)$ & 2.11 & 0.286 & 0.553 & 0.091 \\
\hline Meyve hacmi, V $\left(\mathrm{cm}^{3}\right)$ & 2.67 & 0.425 & 0.392 & 0.095 \\
\hline
\end{tabular}

S.H:Standart hata değerleri

Ercisli ve ark. (2011) fındık çeşitlerinin fiziksel özelliklerini belirledikleri çalışmalarında kabuklu fındık çeşitlerinin geometrik ortalama çap, meyve ağırlığı, küresellik ve yüzey alanı değerlerini sırasıyla 17.52 $22.41 \mathrm{~mm}, 1.80-4.15 \mathrm{~g}, 0.69-0.97,8.21-15.82 \mathrm{~cm}^{2}$ aralı̆̆ında değişim gösterdiklerini bildirmişlerdir. Yenibahar meyvesinin kabuklu örneklerinin küresellik değerleri kabuklu findık meyveleriyle benzerlik gösterirken, geometrik ortalama çap, meyve ağırlığı ve yüzey alanı değerleri kabuklu findık örneklerinden daha küçük olduğu görülmüştür. Ozguven and Vursavus (2005) çam fistığının fiziksel özelliklerini belirlemek için yaptıkları çalışmalarında, meyve hacim ağırlığı ve yığın hacim ağırlığ 1 değerlerini sırasıyla $983.59 \mathrm{~kg} \mathrm{~m}^{-3}$ ve $619.85 \mathrm{~kg} \mathrm{~m}^{-3}$ olarak belirlemişlerdir. Yenibahar meyvesinin meyve hacim ağırlı̆̆ ve yı ̆̆ın hacim ağırlığı değerleri çam fistığı meyvelerinin meyve hacim ağırlığ değerlerinden daha düşük ve yığın hacim ağırlığ 1 değerlerinden daha yüksek değerlerde olduğu görülmüştür. Altuntaş ve Karadağ (2006) burçak, mürdümük ve korunga tohumlarının bazı fiziksel özelliklerini belirledikleri çalışmalarında, tohumların ortalama ve maksimum meyve hacim ağırlıklarını sırasıyla burçak için 1543.32 ve $1762.43 \mathrm{~kg} \mathrm{~m}^{-3}$; mürdümük için 1273.31 ve $325.04 \mathrm{~kg} \mathrm{~m}^{-3}$; korunga için ise; 674.53 ve $782.36 \mathrm{~kg} \mathrm{~m}^{-3}$ olarak bulunmuştur. Yenibahar tohumlarının meyve hacim ağırlığ 
değerleriyle burçak tohumlarının meyve hacim ağırlı̆̆ değerlerinin benzerlik gösterdiği görülmektedir.

\subsection{Renk özellikleri}

Yenibahar meyvesi ve tohumlarının renk ölçümlerindeki karakteristik değerleri sırasıyla $L^{*}$ değeri için, surasiyla 34.2 ve $32.8 ; a^{*}$ değeri için 5.53 ve $5.56 ; b^{*}$ değeri için ise 2.67 ve 1.32 olarak belirlenmiştir (Çizelge 2). Ercisli ve ark. (2011) findık çeşitlerinin fizksel özelliklerini belirledikleri çalışmalarında, kabuklu findık için a* değerlerini 8.67 14.33 aralığında; $b^{*}$ değerlerini ise $13.23-23.82$ aralığında belirlerken, iç findık olarak ise $\mathrm{a}^{*}$ değerlerini $9.44-12.63$ aralığında, $b^{*}$ değerlerini ise 18.08 - 24.01 aralığında tespit etmişlerdir. Bu açıdan yenibahar meyveleri ve tohumlarının $a^{*}$ ve $b^{*}$ değerleri kabuklu fındık ve iç findık meyve örneklerinden daha düşük değerde olduğu görülmektedir.

Çizelge 2. Yenibahar meyveleri ve tohumlarının renk özellikleri

\begin{tabular}{ccccc}
\hline & \multicolumn{2}{c}{ Meyve } & \multicolumn{2}{c}{ Tohum } \\
\hline Renk özellikleri & Ortalama & S.H & 32.8 & 2.34 \\
$L^{*}$ & 34.2 & 1.25 & 5.56 & 0.905 \\
$a^{*}$ & 5.53 & 0.441 & 1.32 & 0.973 \\
$b^{*}$ & 2.67 & 0.623 &
\end{tabular}

S.H: Standart hata değerleri

\subsection{Mekanik özellikler}

Yenibahar meyvesi ve tohumlarının statik sürtünme katsayısı değerleri galvaniz sac, kontrplak, PVC, cam ve lastik olmak üzere 5 farklı sürtünme yüzeylerinde incelenmiştir. Yenibahar meyvesinin farklı sürtünme yüzeyleri için sürtünme katsayısı sırasıyla; 0.27, 0.32, $0.25,0.21$ ve 0.37 yenibahar tohumlarının farklı sürtünme yüzeyleri için sürtünme katsayısı değerleri sirasiyla; $0.32, \quad 0.40,0.31, \quad 0.19$ ve 0.38 olarak belirlenmiştir. Meyvenin statik sürtünme katsayıs1 değerlerinde en düşük değer cam yüzeyde, en yüksek değer ise lastik yüzeyde, tohumların statik sürtünme katsayısı değerlerinde en düşük değer cam yüzeyde, en yüksek değer ise kontrplak yüzeyde bulunmuştur (Çizelge 3).

Çizelge 3. Yenibahar meyveleri ve tohumlarının mekanik özellikleri

\begin{tabular}{ccccc}
\hline Mekanik özellikler & \multicolumn{3}{c}{ Değerler } \\
\hline \multirow{2}{*}{ S1kıştırma testi } & \multicolumn{3}{c}{ Meyve } & Tohum \\
\cline { 2 - 5 } & Ort. & S.H & Ort. & S.H \\
\cline { 2 - 5 } & 25.74 & 4.02 & 11.8 & 0.41 \\
Kırılma kuvveti & & 1.25 & - & - \\
(X ekseni, N) & 27.40 & 8.17 & - & - \\
(Y ekseni, N) & 38.48 & & & 0.018 \\
(Z ekseni,N) & & 0.011 & 0.32 & 0.029 \\
Statik sürtünme katsayıs1 & 0.27 & 0.03 & 0.40 & 0.014 \\
Galvaniz sac & 0.32 & 0.024 & 0.31 & 0.19 \\
Kontrplak & 0.25 & 0.004 & 0.19 & 0.38 \\
PVC & 0.21 & 0.015 & & \\
Cam & 0.37 & & & \\
Lastik & & & & \\
\end{tabular}

S.H.: Standart hata değerleri

Yenibahar meyvesinin sıkıştırma değerleri $60 \mathrm{~mm}$ $\min ^{-1}$ hızında kuvvet uygulanarak kırılma kuvveti değerleri X ekseninde $25.74 \mathrm{~N}, \mathrm{Y}$ ekseninde $27.40 \mathrm{~N}$ ve $\mathrm{Z}$ ekseninde $38.48 \mathrm{~N}$ olarak saptanmıştır. Ancak yenibahar tohumlarının ise sadece $\mathrm{X}$ eksenine kuvvet uygulanabilmiş ve kırılma kuvveti değeri $11.8 \mathrm{~N}$ olarak belirlenmiş, diğer eksenlerde ölçüm yapılamamıştır.

Kibar, (2006) findık çeşitlerinin statik sürtünme katsayılarını belirledikleri çalışmasında, findık çeşitlerinden badem findıkların statik sürtünme katsayısı galvaniz sac ve kontrplak yüzeyler için sırasıyla 0.29 ve 0.24 olarak tespit etmiştir. Statik sürtünme katsayıları açısından findık çeşitlerinin sürtünme katsayısı ile kabuklu yenibahar tohumunun değerlerine yakın sonuçlar göstermiştir.

Shirkole ve ark. (2013) soya fasulyesi tohumlarının statik sürtünme katsayısı değerlerini belirlemek için yapmış oldukları çalışmalarında, TAMS-38 ve JS-335 çeşitlerinin sürtünme katsayısı değerlerinin lastik yüzeyde en yüksek olduğunu belirlemişlerdir. $\mathrm{Bu}$ 
çalışmada yenibahar meyvesinin statik sürtünme katsayısı değerleri de en yüksek lastik yüzeyde bulunmuştur. $\mathrm{Bu}$ açıdan çalışma sonuçları benzerlik göstermektedir.

\section{Sonuc}

Tibbi ve aromatik bitkilerden yenibahar meyvesi ve tohumlarının hasat-harman mekanizasyonu ile hasat sonrası üretim teknolojisine yönelik olarak biyoteknik özelliklerinin bilinmesi, bu amaca yönelik kullanılacak makine ve ekipman ile kullanılacak sistemlerin tasarımında dikkate alınması gerekmektedir. $\mathrm{Bu}$ çalışmada, yenibahar meyvesinin ve tohumlarının sırasıly \% 9.14 ve \% 10.19 nem içeriklerinde elde edilen bazı bulgular aşağıda özetlenmiștir.

-Yenibahar meyvelerinin tohumlara göre daha küresel olduğu görülmüştür.

-Yenibahar meyvesinin gerçek hacim ağırlığ değerleri tohumların gerçek hacim ağırlığına daha yüksek değerde bulunurken, yığın hacim ağırlıkları daha düşük değerde bulunmuştur.

-Yenibahar meyveleri ve tohumlarının statik sürtünme katsayısı cam yüzeyde diğer sürtünme yüzeylerine göre daha düșük değerde bulunmuștur. Buna sebep olarak cam yüzeyin daha düzgün, kaygan ve parlak yüzeye sahip olmasından kaynaklanmıştır.

-Yenibahar meyvelerinin renk ölçüm karakteristiklerinden $L^{*}, b^{*}$ değerleri tohumlara ait değerlerden daha düşük değerde bulunmuştur.

-Yenibahar meyvesinin sıkıştırma testleri sonucu kırılma kuvveti değerleri $\mathrm{X}$ ekseninde $\mathrm{Y}$ ve $\mathrm{Z}$ eksenlerine göre daha düşük bulunmuştur. Yenibahar meyvelerinin kurutma işlemi sonucu nem içeriği \%1214'ler düzeyine düşürüldüğü için araştırma materyali kullanılan yenibahar meyveleri ve tohumlarının depolamaya uygun olduğu görülmektedir.

-Yenibahar meyveleri ve tohumlarının geometrik, volumetrik ve mekanik özellikleri hasat sonrasi uygulamalar olan taşıma, temizleme-sınıflandırma, ürün işleme ve depolamada kullanılacak sistemlerde kullanılacak makine tasarımlarına önemli katkı sunacaktır.

\section{Kaynaklar}

Altuntaş, E., Karadağ, Y., 2006. Some Physical and Mechanical Properties of Sainfoin (Onobrychis sativa Lam.), Grasspea (Lathyrus sativus L.) and Bitter Vetch ( Vicia ervilia (L.) seeds. Journal of Applied Sciences. 6(6): 1373-1379.

Altuntas, E., 2008. Some Physical Properties of Pumpkin (Cucurbita Pepo L.) and Watermelon (Citrullus Lanatus L.) Seeds. Ankara Unıversity
Faculty of Agriculture, Journal of Agricultural Sciences, 14 (1): 62-69.

Altuntas, E., Erkol, M., 2011. The Effects of Moisture Content, Compression Speeds and Axes on Mechanical Properties of Walnut Cultivars. Food and Bioprocess Technology, (7): 1288-1295.

Anonim, 2017a. http://www.tabiat.net.(Erişim tarihi: 21.02.2017)

Anonim, 2017b. https://www.globalherbalsupplies.com. (Erişim tarihi: 14.04.2017).

Anonim, 2017c. http://gernot-katzers-spice-pages.com. .(Erişim tarihi: 03.04.2017)

Anonim, 2017d. http://www.bitkicenter.com. .(Erişim tarihi: 15.05.2017).

Celik A., Ercisli S., Turgut N., 2007. Some physical, pomological and nutritional properties of kiwifruit cv. Hayward. International Journal of Food Sciences and Nutrition, 58: 411-418.

Ercisli, S., Ozturk, I., Kara, M., Kalkan, F., Seker, H., Duyar, O., Erturk, Y., 2011. Physical properties of hazelnuts. International Agrophysics, 25: 115-121.

Gökduman, 2015. Bazı Tıbbi ve Aromatik Bitkilerin Harmanlama ve Ayırma Düzeni İçin FizikoMekanik Özelliklerinin Belirlenmesi. Süleyman Demirel Üniversitesi Fen Bilimleri Enstitüsü, Tarım Makineleri ve Teknolojileri A.B.D. (Yayınlanmamış Yüksek Lisans Tezi) Isparta.

Kibar, H., 2006. Bazı findık çeşitlerinde ürün nem kapsamı ile depolamada etkili şev karakteristikleri arasındaki ilişkiler (Yüksek Lisans Tezi). Ondokuz Mayıs Üniversitesi, Fen Bilimleri Enstitüsü, Tarımsal Yapılar ve Sulama Anabilim Dalı, Samsun.

Jha, S.N., Kingsly, A.R.P., Sangeeta, C., 2005. Physical and mechanical properties of mango during growth and storage for determination of maturity. Journal of Food Engineering, 72: 73-76.

McGuire, R.G., 1992. Reporting of objective colmeasurements. Hortscience, 27: 1254-1255.

Mohsenin, N.N., 1970. Physical properties of plant and animal materials. Gordon and Breach Science Publishers, New York.

Ozgüven, F., Vursavus, K., 2005. Some physical, mechanical and aerodynamic properties of pine (Pinus pinea) nuts. Journal of Food Engineering, 68(2): 191-196.

Peter, K.V. 2004. Handbook of herbs and spices. 2. Cilt, Woodhead Publishing Ltd and CRC Press LLC.

Shirkole, S.S. Kenghe, R.N., Nimkar, P.M., 2013. Moisture dependent physical properties of soybean. International Journal of Engineering Science and Technology, 3(5): 3807-3815.

Yurtlu ,Y.B., Yeşiloğlu, E., Arslanoğlu, F., 2010. Physical properties of bay laurel seeds. International Agrophysics, 24: 325-328. 